\title{
Examining the Relationship between Cultural Intelligence and the Academic Performance of International Students: A Structural Equation Modeling Analysis
}

Yurou Wang ${ }^{1}$, Jihong Zhang ${ }^{2}$

${ }^{1}$ Department of Educational Studies in Psychology, Research Methodology, and Counseling, University of Alabama, USA

${ }^{2}$ Department of Psychological and Quantitative Foundations, University of Iowa, USA

Email: yurou.wang@ua.edu (Yurou Wang); jihong-zhang@uiowa.edu (Jihong Zhang)

\begin{abstract}
Driven by globalization, cultural intelligence (CQ) has become a critical element for human communication. The increasing international student population also calls for an in-depth understanding of CQ, which incorporates metacognitive, cognitive, motivational, and behavioral dimensions that could promote international learning and working performance. This study evaluates the relationship between Cultural Intelligence and international students' academic achievement. Our sample included 452 American students who studied abroad were recruited via Amazon Mechanical Turk. Findings provide partial support for the relationship between CQS factors and participants' self-reported grade point average (GPA). Specifically, students' motivational $(\beta=.188, \mathrm{p}<.01)$ and behavioral $(\beta=.126, \mathrm{p}<.05) \mathrm{CQ}$ scores were found to be significantly correlated with GPA. Such results demonstrate the need for CQ training for students who will study abroad. Further research is needed regarding using CQ to promote students' GPAs and how CQ could change over time.
\end{abstract}


Keywords: cultural intelligence; academic achievement; GPA; international student; structural equation modeling

\section{Examining the Relationship between Cultural Intelligence and the Academic Performance of American Students who Studied Abroad: A Structural Equation Modeling Analysis}

The number of international students reached 5.3 million globally in 2019 (Project Atlas, 2019) and is projected to reach 8 million by 2025 (University of Harvard, 2015). International students represent a vital segment of higher education; in addition to their economic contributions, their distinct cultural perspectives can enhance universities' intellectual environment (e.g., by providing a contrast to often obscure cultural paradigms embedded within a host country) (Lee \& Rice, 2007). International students' capacity "to function and manage effectively in culturally diverse settings" (Ang et al., 2007, p. 336), otherwise referred to as cultural intelligence (CQ), plays an important role in students' academic performance and well-being, as well as in their ability to contribute to the intellectual environment of higher education.

With roots in the fields of business and management (Ramsey et al., 2017), educational researchers have recently applied CQ to explore international students' adjustment (e.g., Shu et al., 2017; Zhang \& Oczkowski, 2016). For example, Lin et al. (2012) noted that CQ was positively correlated with college students' cross-cultural adjustment $(r=0.54)$ when controlling for gender, age, previous overseas experience, English ability, and host country language ability. CQ has also been applied as a moderator to understand culture shock and psychological and sociocultural adjustment among international college students (Presbitero, 2016). Presbitero's (2016) findings indicated that high CQ could reduce the negative influence of culture shock on one's psychological and sociocultural adjustment. Although Presbitero (2016) suggested that CQ could affect international students' adjustment, scholars have yet to evaluate the association between CQ and academic performance, particularly in an American sample. Yet understanding the relationship between CQ and academic performance is essential, as such information could enrich the theoretical and practical value of CQ theory. Academic performance is critical to international students' host and home countries because such performance is closely related to a nation's economy (Poropat, 2009). In terms of personal value, achieving better education and job market competitiveness 
represent primary goals for international students and their families (Roy et al., 2016); the ability to adapt to a new culture and earn high grades is therefore crucial. Overall, the aim of the present study is to evaluate the association between CQ and academic performance to help international students have successful study abroad experiences and potentially boost the economies of their host and home countries.

In this paper, we first provided an overview of the conceptualization of CQ and how CQ may be associated with international students' self-report GPA. Then, we presented confirmatory factor analysis to evaluate the validity of the Cultural Intelligence Scale (CQS) and adopted structural equation modeling (SEM) to identify how different types of CQ (i.e., metacognitive, cognitive, motivational, and behavioral) are related to international students' self-report GPA.

\section{Literature Review}

\section{Cultural Intelligence}

Earley and Ang (2003) proposed the theory of CQ, which integrates Sternberg's (1986) theory of multiple loci of intelligence with other intelligence theories such as the theory of emotional intelligence (Schmidt, 2009; Sternberg \& Detterman, 1986). CQ refers to one's ability to adapt successfully to an unfamiliar cultural context, including interacting effectively with local people in a diverse setting (Earley \& Ang, 2003).

\section{Structure}

There are four aspects of CQ, namely cognitive, motivational, behavioral, and metacognitive (Ang et al., 2007). Cognitive CQ refers to one's actual knowledge of different cultures, including knowledge of cultural values along with the economic, legal, and social systems in different cultures (Brislin et al., 2006). Individuals possessing high cognitive CQ generally have sufficient cultural knowledge, particularly with respect to the fields in which they work or study.

Motivational CQ refers to one's desire and drive to learn about a new culture and cultural differences. Motivation encourages people to acquire new knowledge (Bandura, 2002; Deci \& Ryan, 1985), so motivational CQ drive people to acquire new cultural knowledge. Individuals with high motivational CQ are often eager to develop their cultural knowledge. 
For example, compared to people with lower motivational CQ, those with high motivational CQ tend to be more willing to develop new knowledge and communicate with local people.

Behavioral CQ represents one's ability to interact and communicate with people from different cultures. Individuals exhibiting high behavioral CQ will likely be prepared to interact effectively with people from other cultures, such as by using proper terms with appropriate tones, gestures, and facial expressions (Ang et al., 2007; Gudykunst et al.,1988). People with high behavioral CQ also frequently seek to imitate local people's behavior. Because these individuals are generally sensitive to behaving inappropriately, they can modify their behavior in future interactions.

Metacognitive CQ encompasses the intellectual process of adopting and understanding a different culture (Ang et al., 2007), such as by relating to another person's cultural background. An individual with high metacognitive CQ should be aware of other people's cultural norms and preferences during interactions (Triandis, 2006) and carefully consider how they should speak and behave. Such considerations are key to social integration (Thompson, 2018). Importantly, although the interactions among these different forms of CQ remain somewhat unclear, Ang and colleagues (2007) pointed out that people with high cognitive, motivational, and metacognitive CQ do not necessarily have high behavioral CQ.

\section{Cultural Intelligence and Outbound International students}

According to UNESCO (2020), international students refer to "Students who have crossed a national or territorial border for the purpose of education and are now enrolled [in school] outside their country of origin." For the purposes of this paper, we focused primarily on American students who have had experience of studying abroad, so in this paper international students refers to those who were engaging in outbound mobility programs.

CQ is a relatively new construct, therefore, most studies thus far have indicated that CQ is associated with international students' adjustment (e.g., Lin et al., 2012; Presbitero, 2016). More specifically, Ward et al. (2011) respectively analyzed the four types of CQ as predictors of cross-cultural adjustment in a longitudinal study of international students. The bivariate correlation results showed that students with high motivational CQ experienced fewer psychological symptoms and sociocultural adjustment problems compared to students with lower motivational CQ.

There are only a few research focus on the impact of CQ on the American students' studying abroad experience. Most of the research were focusing on how CQ could promote studying 
abroad experience. According to Racicot and Ferry (2016) motivational CQ and metacognitive CQ could promote US students to pursuit more working or studying abroad experience. Holtbrügge and Engelhard (2016) also found that Individual Motivation and Cultural Boundary could promote American university students' CQ, which could significantly support intercultural interactions. To our knowledge, few study examined CQ's impact on academic performance or GPA.

CQ and Academic Performance. The relationship between CQ and academic performance or GPA among international students warrants close attention for three reasons. First, international students generally choose to study abroad to receive a better education; they and their families are concerned about their academic performance (Li et al., 2010). Several factors have been found to affect international students' academic performance, among which adjustment has been deemed critical (Andrade, 2006; Lin \& Yi, 1997; Poyrazli et al., 2002). As indicated earlier, a connection exists between CQ and international students' adjustment; a potential link may therefore manifest between CQ and academic performance.

Second, although few scholars have evaluated the relationship between CQ and academic performance, abundant research has indicated a significant relationship between CQ and several work-related intercultural characteristics such as task performance, citizen performance, job performance, and leadership performance (Chen et al, 2010; Chen et al., 2012; Presbitero, 2016). The correlation between CQ and job performance implies a potential association of CQ with academic performance. In a sample of Philippine laborers in Taiwan, Chen et al. (2011) found that Philippine laborers with higher CQ performed better than those with lower CQ. Lee et al. (2013) also confirmed the direct impact of CQ on job performance via transformational leadership and social support among a group of expatriate managers. By examining individual dimensions of CQ, Ang and colleagues (2007) discovered that metacognitive and behavioral CQ predicted task performance (e.g., solving problems and meeting culturally diverse partners' expectations). Motivational and behavioral CQ were each directly associated with contextual performance, where role expectations are less constructed and culturally specific. General cognitive theory suggests that performance tends to remain consistent across contexts (Kuncel et al., 2004); we can thus infer that academic performance, task performance, and job performance may be transferable.

Third, CQ shares similarities with social and emotional intelligence, as CQ emphasizes the ability to understand others, and caring for other people's emotion in an intercultural context (Ang et al., 2015). Several studies have shown that social and emotional intelligence each 
exert a direct and positive impact on academic performance (Bance \& Acopio, 2016; Gumora \& Arsenio, 2002; Olson, 2008). The effect of CQ on academic performance may also be direct and positive. Ultimately, the associations among CQ, adjustment, and intercultural performance, as well as CQ's commonalities with social and emotional intelligence, indicate that CQ may be related to academic performance.

Academic performance is a common term that refers to a range of academic indicators. In this paper, academic performance captures educational outcomes, which are often measured by GPA (Ward et al., 1996, p. 2). GPA is one of the most readily available assessments of academic performance (York et al., 2015), and many studies on international students' academic performance have referred to GPA as an evaluative measure. Based on the preceding discussion, we hypothesize the following:

Hypothesis 1: The four-factor structure of the Cultural Intelligence Scale holds in our sample of international students.

Hypothesis 2: Metacognitive, cognitive, motivational, and behavioral cultural intelligence are each significantly associated with international students' academic performance.

\section{Method}

The relationships between CQ and international students' self-report GPA were assessed through two studies. To examine Hypothesis 1, Study 1 involved confirmatory factor analysis (CFA) to evaluate the validity of the CQS. We then adopted SEM to investigate the link between CQ and students' self-report GPA; specifically, the four dimensions of CQ were taken as correlated variables, and international students' GPAs represented the outcome variable.

\section{Participants and Procedures}

We recruited the sample for Study 1 via Amazon Mechanical Turk (MTurk). MTurk has become an increasingly popular platform for conducting survey research, as it facilitates access to a large and diverse population at a relatively low cost to investigators (Hauser \& Schwarz, 2016). MTurk functions as a virtual labor market where registered "workers" complete online tasks for pay. During registration, all MTurk workers are required to electronically sign a Participation Agreement confirming they are at least 18 years of age. We also included one checking item: Did you have more than 6 month of studying abroad experience? If the participant answered yes, they would be able to continue the survey. If the participant answered no, they will be filtered out of. The response rate is $100 \%$ due to MTurk 
feature of force completion to get the incentive. Every participant was paid 1 USD for finishing the survey.

MTurk workers who were most representative of the target population were recruited for this study; participants were eligible if they either had been or were currently U.S. students who had attended or graduated from a foreign university or college. Participants logged into MTurk before being redirected to our online survey in Qualtrics. Participants were then informed of the nature of this research and were informed that they could opt out at any time during the survey. They were also informed that all data collected would be de-identified to protect their privacy.

After hosting the survey via Qualtrics for a 4-month period, 678 participants had responded; however, many surveys included missing values. 219 out of 678 are removed because of the missing values and extreme cases of item responses based on the Mahalanobis distance before conducting CFA. After omitting surveys with missing values and extreme cases, 454 surveys remained for validation of the CQS. Two cases are further removed because of the missingness of GPA. Finally, 452 valid cases are used to conducted CFA. The final sample $(N=452)$ in Study 1 consisted of 194 women (43.11\%) and 256 men (56.89\%) between 20 and 50 years old $(M=33.74, S D=7.83)$.

In order to test Hypothesis 2, in Study 2, we performed SEM analysis. The 277 out of 452 cases includes GPA item with the continuous scale (round 2) and the 175 out of 452 cases includes GPA with the ordinal scale. Using GPA mixed with continuous scale and ordinal scale will lead to bias because the ordinal scale has less information than continuous scale. We decide to use this sub-sample $(N=277)$ to perform SEM analysis. To be specific, in the first round of data collection (Study 1), participants only provided letter rankings for GPA (e.g., A, B, C, F) without specifying precise numerical values. The sample size of Round 1 is 175. Since, those data in first round could not be used for SEM, in second round (Study 2), we distributed the same survey but only the GPA question changed to a new group of participants and asked them to provide their GPA to two decimal places in the second round of data collection; the sample size of Round 2 is 277 . Because the reasons above, we only use the data from second round. Therefore, the sample size for SEM analysis is 277. 


\section{Measures}

\section{Cultural Intelligence Scale}

Participants completed the CQS (Ang et al., 2007), a 20-item scale containing questions related to the four dimensions of $\mathrm{CQ}$ (i.e., metacognitive, cognitive, motivational, and behavioral). Items were scored on a 7-point Likert scale $(1=$ "strongly disagree", $7=$ "strongly agree"; no items were reverse scored), with higher scores indicating higher CQ. More than $90 \%$ of quantitative research related to CQ has used the CQS to evaluate this construct (Fang et al., 2018), and the scale's reliability and validity are well documented (Ang et al., 2007; Huff et al., 2014); thus, we adopted the CQS to measure international students' CQ.

We adapted the original 20-item CQS per the recommendations of Ang et al. (2007). Five doctoral students in the Educational Measurement program reviewed all scale items and recommended that the item "I know the economic and the legal system of other cultures" be split into two items: one item related to the economic system and another related to the legal system. Finally, the revised 21-item CQS was administered to 623 participants.

As shown in Table 2, all four subscales (Cognitive, Metacognitive, Motivational, and Behavioral CQ) of the modified CQS (See Appendix A for a complete scale). Sample items from the Metacognitive CQ subscale included "I am conscious of the cultural knowledge I use when interacting with people with different cultural backgrounds." and "I adjust my cultural knowledge as I interact with people from a culture that is unfamiliar to me." Sample items from the Cognitive CQ subscale included "I know the economic system of other cultures" and "I know the rules (e.g., vocabulary, grammar) of other languages." The Motivational CQ subscale consisted of items such as "I enjoy interacting with people from different cultures.” Finally, behavioral CQ (i.e., one's ability to behave appropriately when interacting with people of different cultures) was assessed using items such as "I change my verbal behavior (e.g., accent, tone) when a cross-cultural interaction requires it" and "I vary the rate of my speaking when a cross-cultural situation requires it."

Outcome Variables. Self-report GPA was taken as an indicator of academic performance and as the outcome variable of culture intelligence in this study. We used international students self-report cumulative GPA as an indicator for academic performance. Participants' GPAs enabled a comparison of standardized scores. Each participants' self-reported GPA 
was rounded to the nearest hundredth. Of the total sample $(N=452), 175$ participants did not report their GPA using the continuous scales and were thus excluded from Study 2.

Data Analysis. All analyses were conducted using the lavaan package 0.6-3 (Rosseel, 2012) in R ver. 3.5.2 (R Core Team, 2019). 219 out of 678 are removed because of the missing values of item responses (See Table 2). Two cases are further removed because of the missingness of GPA. Finally, 452 valid cases are used to conducted CFA. For further SEM analysis, because the 277 out of 452 cases includes GPA with the continuous scale, we decide to use this subsample $(\mathrm{N}=277)$ to perform SEM.

To examine hypothesis 1 , we conduct CFA for four subscale of cultural intelligence. All CFA models were statistically identified by fixing all latent factor means to 0 and latent factor variances to 1, after which all item intercepts, item factor loadings, and item residual variances were estimated. The model fit statistics reported in Table 1 include the chi-square statistic, the scaling factor (in which values different from 1.000 indicate deviations from normality), degrees of freedom, and $p$-values (non-significance is desirable for a good fit). Given the sensitivity of the chi-square statistic to sample size, the comparative fit index (CFI), Tucker-Lewis Index (TLI), root mean square error of approximation (RMSEA), and maximum likelihood (ML)-based standardized root mean squared residual (SRMR) were reported to evaluate the adequacy of each model. These indices provide a reliable evaluation of goodness-of-fit; simulation studies have found them to be least influenced by sample size (Fan et al., 1999). CFI and TLI values should exceed 0.90 for an acceptable model fit (Bentler, 1990), although values approaching 0.95 are preferable (Hu \& Bentler, 1999). In addition, RMSEA and SRMR values close to or lower than 0.05 are acceptable $(\mathrm{Hu} \&$ Bentler, 1999). As reported in Table 1, nested model comparisons were conducted using the rescaled $-2 \Delta \mathrm{LL}$ with degrees of freedom equal to the rescaled difference in the number of parameters between models (i.e., a rescaled likelihood ratio test). The reliability of each latent factor was estimated using coefficient omega $(\omega)$. Coefficient omega is considered a practical alternative to coefficient alpha in estimating the measurement reliability of factor scores.

To examine hypothesis 2, SEM analyses were performed for Study $2(N=277)$ to investigate the relationship between international students' CQ and self-report GPA. To eliminate the potential confounding effects of gender and age, the regression coefficients of these two variables on CQ and academic performance were estimated. If the estimated coefficients were not significant, then the confounding effects of gender and age were considered weak. 
Relationships between the four types of CQ and GPA were then evaluated by controlling for variables such as gender and age.

\section{Results}

\section{Data Quality}

The data quality of each sample in Study 1 and Study 2 was examined using the statistical screening methods of personal reliability and the Mahalanobis distance (DeSimone et al., 2015). We used personal reliability, which Douglas Jackson introduced at a meeting of the Society of Multivariate Experimental Psychology (Jackson, 1976), to examine each respondent's consistency within each measure. The personal reliability coefficient was .956 , indicating good response consistency. Recent evidence has suggested that the Mahalanobis distance is effective for identifying inattentive response patterns (Ehlers et al., 2009). To detect outliers, we computed the Mahalanobis distance for each respondent. Two extreme cases were ultimately removed from further analysis.

\section{Cultural Intelligence Confirmatory Factor Analysis}

As shown in Table 1, the hypothesized one-factor model (Model 1) resulted in a poor model fit: scaled $\chi^{2}(189)=1796.457, p<.01, \mathrm{CFI}=0.66$, TLI $=0.62, \mathrm{RMSEA}=0.137, \mathrm{SRMR}=$ 0.107. Although each item exhibited a moderate standardized factor loading (standardized loadings ranged from .56 to .75), a single latent factor did not adequately describe the relationship pattern across these 21 items. Sources of local misfit were identified using the normalized residual covariance matrix. Relatively larger positive residual covariances were observed among subscale items, indicating that these items were more closely related than was predicted by the single-factor model. Modification indices corroborated this pattern, further suggesting additional relationships among the subscale items.

We tested the need to separate CQ factors by specifying a 4-factor model (Model 2) in which items 1-4 reflected metacognitive CQ, items 5-11 reflected cognitive CQ, items 12-16 reflected motivational CQ, and items 17-21 reflected behavioral CQ. All latent factors were allowed to correlate. As displayed in Table 1, Model 2 demonstrated an acceptable but not good fit to the data: scaled $\chi^{2}(183)=471.313, p<.01, \mathrm{CFI}=.94, \mathrm{TLI}=.93$, RMSEA $=.06$, $\mathrm{SRMR}=.05$. Furthermore, estimated correlations between the four latent factors were moderate in magnitude (.70-.88), although none was so large to suggest that any two factors 
were indistinguishable. Thus, the 21 items appeared to measure four separate but related constructs. Further examination of the local fit based on normalized residual covariances and modification indices indicated that items COG1 (I know the legal system of other cultures) and COG2 (I know the economic system of other cultures) had high positive normalized residual covariances, implying additional residual covariance between these items. The likelihood ratio test comparing the change in chi-square values between models was statistically significant $(\Delta \chi[d f=6]=940.1, p<0.01)$, suggesting that Model 2 fit the data significantly better than Model 1.

Accordingly, we added the correlated residuals between item COG1 and COG2 (Model 3; see Table 2 in Appendix B). Model comparison results suggested that adding the correlated residual will significantly improve model fit $(\mathrm{MI}[d f=1]=184.66, \mathrm{p}<0.01)$. Items COG1 and COG2 were split from a single, original item (i.e., the economic and legal systems of other cultures, respectively) and thus might share similar wording. Accordingly, we added this correlated residual and refitted the model (Model 3). The results for Model 3 (Table 1) indicate that including this correlated residual substantially improved the absolute model fit and met the criteria for a good model fit: scaled $\chi^{2}(182)=414.326, p<.01$, CFI $=.95$, TLI $=.943$, RMSEA $=.05$. The likelihood ratio test comparing the change in chi-square values between models was statistically significant $(\Delta \chi[d f=1]=51.619, p<0.01)$. Therefore, with respect to model comparisons, we used Model 3 as the final measurement model for the CQS. Next, we estimated factor loadings and reliability of four subscales in Model 3. As listed in Table 2, all factor loadings were statistically significant. The omega reliability coefficients suggested that all latent factor scores were reliable (i.e., $\omega>.83$; see Table 2). Table 3 show that all CQ factors are moderately correlated $(0.5<\mathrm{r}<0.7)$. Collectively, these findings provide evidence of the construct validity and dimensionality of our revised 4-factor model. 


\section{Cultural Intelligence Structural Equation Modeling}

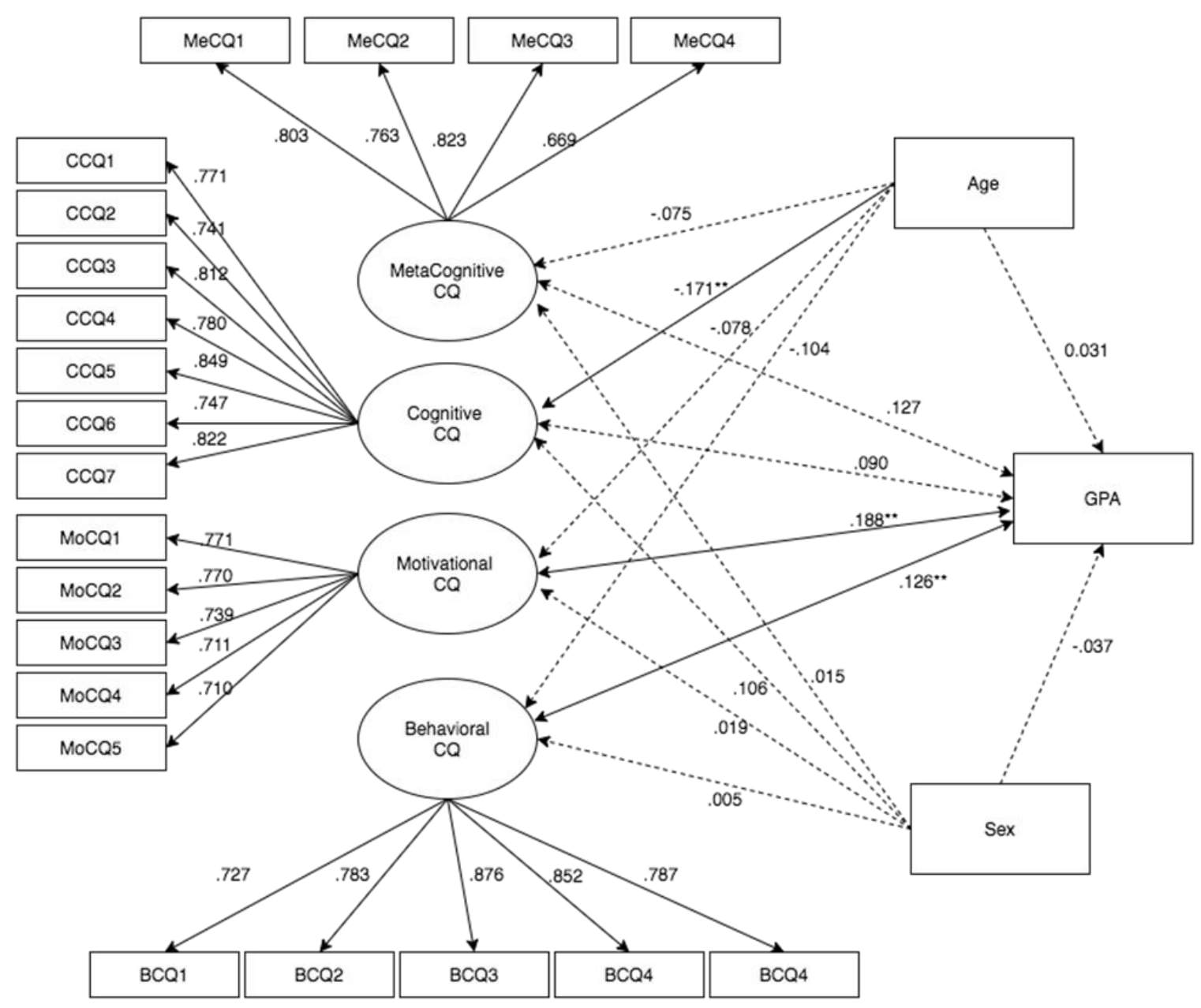

Figure 1 SEM Estimation Among Latent Factors and GPA Regressed on Dimensions

Note. The solid line suggest the significant coefficient and the dashed line suggest that the coefficient is not significant at the level of .05.

Figure 1 presents the measurement model (left) and structural model (right). Regarding the structural model, to investigate the confounding effects of age and gender on international students' CQ and GPA, we included these two variables in our SEM models as control variables. We explored the associations between CQ factors and GPA using Pearson correlation coefficients. Goodness-of-fit indices for the structural model conveyed an acceptable model fit for CFI and TLI $(C F I=.926, T L I=.913)$ but a poor fit based on RMSEA and SRMR $(R M S E A=.059, S R M R=.051)$. Modification indices suggested that adding the residual covariances between items BCQ3 (I vary the rate of my speaking when a cross-culture situation requires it) and BCQ4 (I change my nonverbal behavior when a crossculture situation require it) on the Behavioral CQ subscale and those between items CCQ2 (I 
know the economic systems of other cultures) and CCQ5 (I know the marriage systems of other cultures) on the Cognitive CQ subscale may enhance the model fit substantially. After the further examination, we think that BCQ3 and BCQ4 have correlated residuals maybe because they have similar wordings "when a cross-cultural situation requires it". Similarly, CCQ2 and CCQ5 also have similar wording "system of other culture". The global model fit indeed improved after adding these two parameters $(C F I=.940, T L I=.928, S R M R=.049)$. Checking the modification indices again revealed no meaningful improvement. Thus, we decided to fit this model to the data. Our estimation results and model interpretation are discussed below.

Table 3 presents all standardized estimates (i.e., path coefficients), variances, and correlations among international students' CQ scores, GPA, gender, and age. First, the estimated coefficients between age and GPA indicated that the estimated effects of the age at which one began to study abroad on all CQ factors were not statistically significant aside from cognitive CQ scores $(\beta=-0.171, p<.05)$; that is, older individuals can be expected to have lower cognitive CQ scores after controlling for the effects of gender and GPA. Second, similar to age, the relationship between gender and GPA was relatively weak. No significant differences were observed in men's and women's CQ scores; thus, age and gender each appeared to have negligible effects on GPA after controlling for the effects of CQ.

The relationships between CQ scores and GPA were complicated. The magnitude of path coefficients between each CQ scores with participants' GPA revealed that only motivational CQ scores and behavioral CQ scores were significantly positively correlated with GPA in universities when studying abroad. The model did not indicate that participants' metacognitive or cognitive CQ scores were significantly associated with their self-report GPA in higher education. Essentially, our results support the hypothesis 2 that after controlling the effects of CQ scores, the confounding effects of gender and age on GPA were not statistically significant at the 0.05 level ( $p=0.323$ and $p=0.177$, respectively). Our findings partially support the hypothesis 2 that some types of CQ (i.e., motivational CQ and behavioral CQ) are associated with international students' self-report GPA. 


\section{Discussion}

\section{Limitation}

There are some limitations of this study. Firstly, we used self-report GPA, the accuracy of the data might be contaminated by recall bias or the tendency of students to report higher GPA (Crede \& Kuncel, 2013). However, we believe even there might be some bias, self-reported GPA still provide valuable information, as objective source GPA were hard to access (Caskie, Sutton \& Eckhardt, 2014). Secondly, we did not control for the time of studying abroad. Further research should address how CQ change over time. Nonetheless, we required our participants to have more than six month studying abroad experience, so this should somewhat control for the time effect on CQ. In this way, the potential negative impact of not controlling for time could be minimized

\section{Theoretical Contributions}

This study is one of the first to evaluate the validity of the CQS in a higher education environment and to unveil a direct relationship between CQ subscale scores and self-report GPA. The results offer strong evidence of the psychometric validity of the CQS based on our sample, consistent with other studies (Lin et al., 2012; Presbitero, 2016; Ward et al., 2009). The benefit of splitting a single cognitive item (i.e., economic and legal systems of other cultures) into two items was unclear, as we needed to allow for correlated residuals between the two new items. Further research is therefore needed to evaluate other forms of validity before the CQS can be used to inform interventions or practice related to international students.

We drew upon the extant literature in proposing that the four CQS factors would be positively correlated with international students' academic performance. As previous research has revealed associations between the CQS and indicators of psychological adjustment, as well as with job performance (Ang et al., 2007), examining performance relative to CQ within a higher education environment is a natural extension of such work. Other scholars have identified positive correlations between different competencies (e.g., emotional and socioemotional competencies) and academic performance. For example, in a longitudinal study of children's emotion-based knowledge, which some consider an aspect of emotional intelligence, such knowledge at age 5 positively predicted children's academic competence at age 9 (Izard et al., 2001). 
Overall, the results of our study provide partial support for the hypothesis that a significant relationship exists between CQS factors and students' self-reported GPA after controlling for the confounding effects of gender and age. We found that higher motivational $(\beta=.188, p$ $<.05)$ and behavioral $(\beta=.126, p<.05)$ factor scores were significantly related to higher GPA when studying abroad during college, whereas metacognitive and cognitive factors were not. Thus, we believe this pattern may reflect a difference in the functional utility of applied versus content intelligence as measured by the CQS. Motivational and behavioral factors of the CQS focus on one's desires, motives and actions to function successfully within a foreign culture. Comparatively, metacognitive and cognitive dimensions focus on one's knowledge of cultural content and cultural systems (e.g., the host country's legal system). Applied cultural competencies might therefore represent the degree to which an individual has learned to navigate a culturally different academic system successfully.

Even though cognitive dimension did not show significant association with self-reported GPA, we found there was a significantly negative relationship between age and cognitive CQ which indicated that older international students have lower cognitive CQ comparing to younger international students. Such relationship can be explained from the perspective of developmental psychology and neuroscience. Older people have less cognitive plasticity and brain capacity to adapt to a new environment due to the decrease of grey matter in prefrontal cortex (Fertonani, Brambilla, Cotelli \& Miniussi, 2014; Lindenberger \& Mayr, 2014; Steggener et al., 2009). This finding brought the attention to the elderly group of international students. Even older people only make a small percentage of international student group, they may need more support from the institution. This area needs more attention and further research.

However, the relationship between international students' academic performance and CQ may be more complicated than we anticipated. For example, the results of our research and a study conducted within a Turkish context (Şahin,Gürbüz, Köksal \& Ercan , 2013) differed; in a group of Turkish domestic students who had studying abroad experience, metacognitive and cognitive CQ appeared to predict students' GPA significantly. This discrepancy suggests that the association between CQ and academic performance could vary from culture to culture. Although we would be remiss to generalize this pattern based upon culture alone, the topic calls for further study. 


\section{Practical Contributions}

Other than expanding the CQ theory, our findings also have practical value. Confirming the relationship between international students' $\mathrm{CQ}$ and academic performance, along with the significant effects of this association on cultural adjustment, underscores the need for training to improved international students' CQ. Crowne (2008) argued that training programs about CQ should be tailored to suit individuals' unique degree of cultural understanding. Explorations of CQ training have largely focused on the business and management fields. For instance, MacNab (2012) developed a 7-stage CQ training framework to improve managers' $\mathrm{CQ}$ in a cross-cultural setting, and this framework proved to be effective; participants proceeded through stages including awareness development, experiential instructions provided, pre-experience check, new cultural experience, post-experience internalization, teacher feedback and communication, and group discussion and social sharing.

CQ training has also been conducted in the education domain. The Victoria University of Wellington presented an intercultural training intervention to improve students' CQ, which included six lectures, one simulation game, and one behavior modification session (Fischer, 2011). A pre- and post-test of CQ was also conducted. Findings from 49 participants showed that their cultural essentialism scores increased, but their cognitive and metacognitive CQ scores declined. No significant increase in participants' CQ was observed following the training, presumably because the researcher used a small sample size and the course only lasted 1 week. Although this intervention did not succeed, its results are still enlightening. International students may benefit from this type of training before and after entering their host country. However, more research is needed to determine whether MacNab's (2012) framework could be applied to CQ training with international students. More practical efforts are also needed to discover an effective means of teaching international students about CQ.

\section{Future Directions}

In subsequent research, scholars could consider numerous other factors (e.g., host country students' language proficiency) that may influence international students' CQ and academic performance. Moreover, the length of students' study abroad experiences could be considered. Wang et al. (2015) found that international students' CQ can change over time, but the authors' results were only applicable to Chinese international students within a brief time frame (i.e., 3 months). Future studies could focus on how CQ changes over a longer period and how to improve international students' CQ in a higher education settings. 
Table 1 Model Fit Statistics and Model Comparison

Model Fit Statistics and Model Comparison

\begin{tabular}{|c|c|c|c|c|c|c|c|c|}
\hline \multirow[b]{2}{*}{ Models } & \multirow[b]{2}{*}{ scaled $\chi^{2}$} & \multirow[b]{2}{*}{ df } & \multicolumn{4}{|c|}{ Model Fit Indices } & \multicolumn{2}{|c|}{ Model Comparisons } \\
\hline & & & CFI & TLI & RMSEA & SRMR & $\Delta \chi^{2}$ & p value \\
\hline Model 1 & 1796.457 & 189 & 0.656 & 0.618 & 0.137 & 0.107 & & \\
\hline Model 2 & 483.171 & 183 & 0.936 & 0.926 & 0.060 & 0.053 & $940.1^{* *}$ & $p<.001$ \\
\hline Model 3 & 414.326 & 182 & 0.950 & 0.943 & 0.053 & 0.050 & $51.62^{* *}$ & $p<.001$ \\
\hline
\end{tabular}

Notes: CFI, comparative ft index; TLI, Tucker-Lewis Index; SRMR, standardized root mean square residual; RMSEA, root mean square error of approximation.

$* p<.05, * * p<.01$ 
Table 2 Summary of Item Responses

Summary of Item Responses and Revised Four-Factor Solution for Culture

Intelligence Survey

Factor Loadings

Questionnaire Items

\begin{tabular}{lllllll}
\hline 1 & 2 & 3 & 4 & Mean & SD & Missin \\
\end{tabular}

Metacognitive CQ $(\omega=\mathbf{0 . 8 3 8}, \mathrm{p}$

$<\mathbf{0 . 0 5 )}$

1. I am conscious of the cultural knowledge I use when interacting with people with different culture

backgrounds.

2. I adjust my culture knowledge

as I interact with people from a $0.727^{* *}$

culture that is unfamiliar to me.

3. I am conscious of the cultural knowledge I apply to cross-culture

interactions.

4. I check the accuracy of my cultural knowledge as I interact with people from different

cultures.

Cognitive CQ $(\omega=\mathbf{0 . 9 0 8}, \mathrm{p}<$ 0.05)

5. I know the legal systems of other cultures.

6. I know the economic systems of other cultures.

7. I know the rules (e.g., vocabulary, grammar) of other languages.

8. I know the cultural values and religious beliefs of other cultures.

9. I know the marriage systems of other cultures.

10. I know the arts and crafts of other cultures. 
nonverbal behaviors in other cultures.

Motivational CQ $(\omega=\mathbf{0 . 8 6 0}, \mathbf{p}<$ 0.05)

12. I enjoy interacting with people from different cultures.

13. I am confident that I can socialize with locals in a culture

that is unfamiliar to me.

14. I am sure I can deal with the stresses of adjusting to a culture

that is new to me.

15. I enjoy living in cultures that are unfamiliar to me.

16. I am confident that I can get accustomed to the shopping

conditions in a different culture.

Behavioral CQ $(\omega=\mathbf{0 . 9 1 6}, \mathbf{p}<$ 0.05)

17. I change my verbal behavior (e.g. accent, tone) when a cross$0.799^{* *} \quad 5.002 \quad 1.462$ cultural interaction requires it.

18. I use pause and silence differently to suit different cross$0.810^{*}$ 4.86

cultural situation requires it.

19. I vary the rate of my speaking when a cross-cultural situation

requires it.

20. I change my nonverbal behavior when across-cultural

situation requires it.

21. I alter my facial expressions when a cross-cultural requires it. 


\begin{tabular}{|c|c|c|c|c|c|}
\hline \multicolumn{6}{|c|}{ Parameter Estimate } \\
\hline & MetaCQ & $\underline{\mathrm{Cog} C \mathrm{Q}}$ & MotCQ & BehCQ & GPA \\
\hline MetaCQ & 0.802 & & & & 0.127 \\
\hline $\operatorname{Cog} C Q$ & 0.513 & 1.408 & & & 0.090 \\
\hline MotCQ & 0.657 & 0.557 & 0.692 & & $0.188^{* * *}$ \\
\hline BehCQ & 0.639 & 0.638 & 0.654 & 1.137 & $0.126^{*}$ \\
\hline Age & -0.075 & $-0.171^{* *}$ & -0.078 & -0.104 & 0.031 \\
\hline Gender & 0.015 & 0.106 & 0.019 & 0.005 & -0.037 \\
\hline
\end{tabular}

Note. MetaCQ: Metacognitive CQ; CogCQ: Cognitive CQ; MotCQ: Motivational CQ; BehCQ: Behavioral CQ; The diagonal values of CQ factor table represent the factor variances (i.e. 0.802 is the variance of Metacognitive CQ).

$* p<.05 . * * p<.01 * * * . p<.001$

\section{Appendix A CQ Scale}

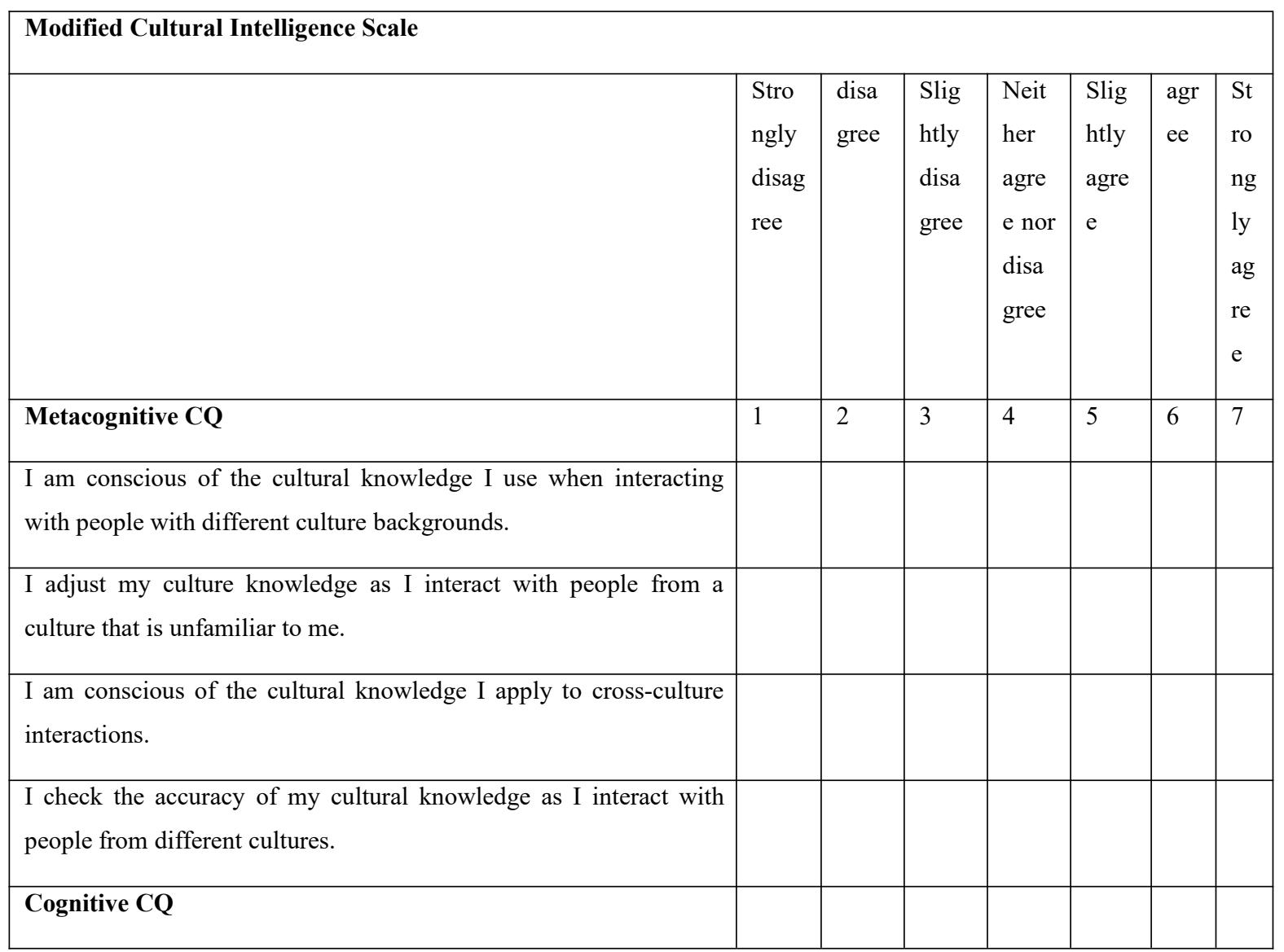




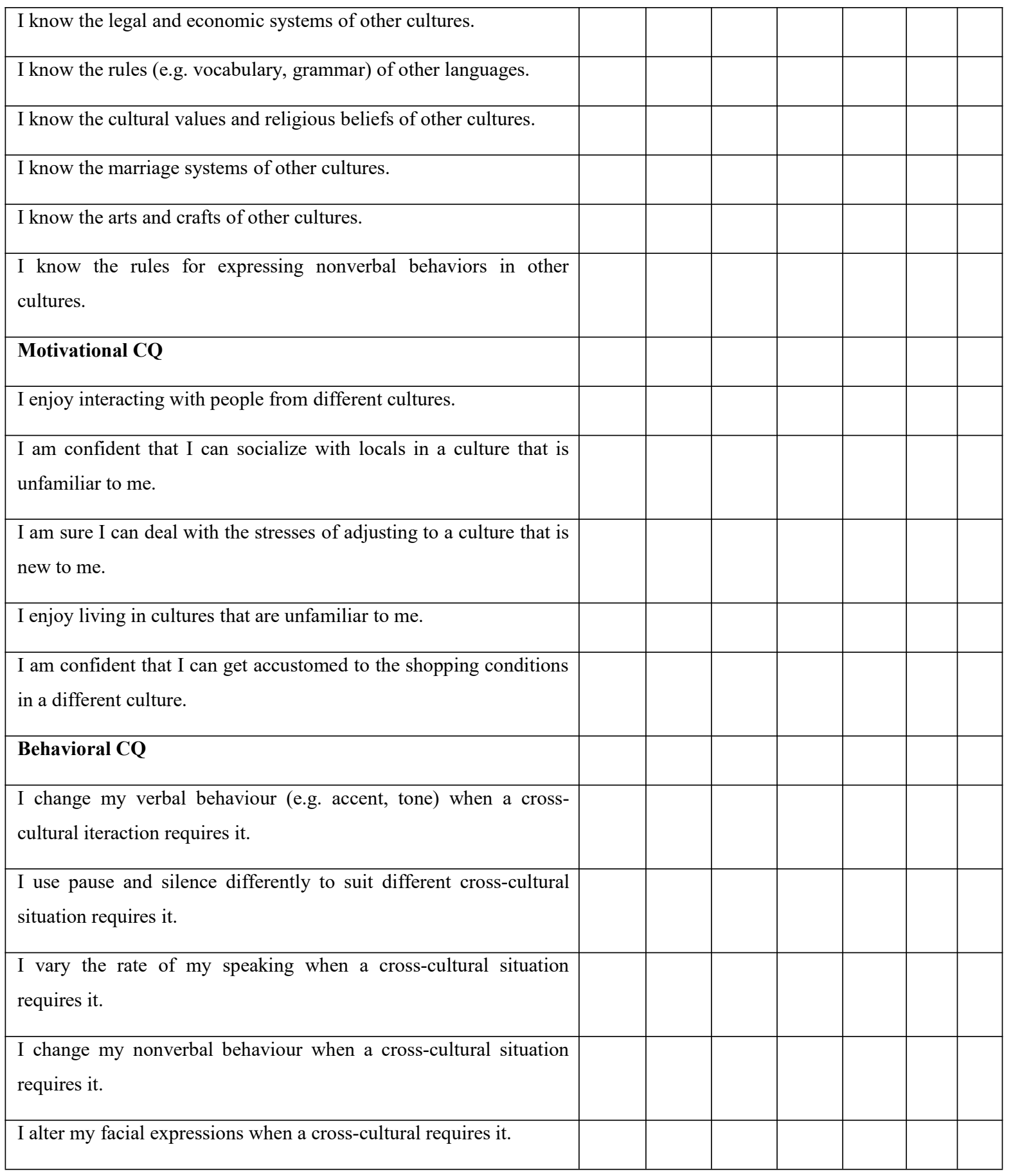

\section{References}

[1] Andrade, M. S. (2006). International students in English-speaking universities: Adjustment factors. Journal of Research in International Education, 5(2), 131-154.

[2] Ang, S., Van Dyne, L., Koh, C., Ng, K. Y., Templer, K. J., Tay, C., \& Chandrasekar, N. A. (2007). Cultural intelligence: Its measurement and effects on cultural judgment and decision making, cultural adaptation and task performance. Management and Organization Review, 3(3), 335-371. 
[3] Ang, S., Van Dyne, L., \& Rockstuhl, T. (2015). Cultural intelligence: Origins, conceptualization, evolution and methodological diversity. In Gelfand, M., Chiu, C. Y., \& Hong, Y. Y. (Eds.), Handbook of Advances in Culture and Psychology, Vol. 5 (pp. 273-323). Oxford University Press.

[4] Bance, L. O., \& Acopio, J. R. B. (2016). Exploring Emotional Intelligence and Academic Performance of Filipino University Academic Achievers. International Journal of Psychological Studies, 8(3).

[5] Bandura, A. (2002). Social cognitive theory in cultural context. Applied psychology, 51(2), 269-290.

[6] Bentler, P. M. (1990). Comparative fit indexes in structural models. Psychological Bulletin, 107(2), 238-246.

[7] Brislin, R., Worthley, R., \& Macnab, B. (2006). Cultural intelligence understanding behaviors that serve people's goals. Group \& Organization Management, 31(1), 40-55.

[8] Caskie, G. I., Sutton, M. C., \& Eckhardt, A. G. (2014). Accuracy of self-reported college GPA: Gender-moderated differences by achievement level and academic selfefficacy. Journal of College Student Development, 55(4), 385-390.

[9] Chen, A. S. Y., Lin, Y. C., \& Sawangpattanakul, A. (2011). The relationship between cultural intelligence and performance with the mediating effect of culture shock: A case from Philippine laborers in Taiwan. International Journal of Intercultural Relations, 35(2), 246-258.

[10] Chen, G., Kirkman, B. L., Kim, K., Farh, C. I., \& Tangirala, S. (2010). When does intercultural motivation enhance expatriate effectiveness? A multilevel investigation of the moderating roles of subsidiary support and cultural distance. Academy of Management Journal, 53, 1110-1130.

[11] Chen, X. P., Liu, D., \& Portnoy, R. (2012). A multilevel investigation of motivational cultural intelligence, organizational diversity climate, and cultural sales: Evidence from U.S. real estate firms. Journal of Applied Psychology, 97, 93-106.

[12] Credé, M., \& Kuncel, N. R. (2013). Self-reported grades and GPA. International guide to student achievement, 49-50.

[13] Crowne, K. A. (2008). What leads to cultural intelligence? Business Horizons, 51(5), 391-399. https://doi.org/10.1016/j.bushor.2008.03.010 
[14] Deci, E. L., \& Ryan, R. M. (1985). The general causality orientations scale: Selfdetermination in personality. Journal of Research in Personality, 19(2), 109-134.

[15] Deng, L., \& Gibson, P. (2009). Mapping and modeling the capacities that underlie effective cross-cultural leadership: An interpretive study with practical outcomes. Cross Cultural Management: An International Journal, 16(4), 347-366.

[16] DeSimone, J. A., Harms, P. D., \& DeSimone, A. (2015). Best practice recommendations for data screening. Journal of Organizational Behavior, 36, 171-181.

[17] Earley, P. C., \& Ang, S. (2003). Cultural intelligence: Individual interactions across cultures. Stanford University Press.

[18] Ehlers, C., Greene-Shortridge, T. M., Weekley, J. A., \& Zajack, M. D. (2009, March). The exploration of statistical methods in detecting random responding. Paper presented at the Annual Meeting of the Society for Industrial/Organizational Psychology, Atlanta, GA.

[19] Fan, X., Thompson, B., \& Wang, L. (1999). Effects of sample size, estimation methods, and model specification on structural equation modeling fit indexes. Structural Equation Modeling: $\quad$ A $\quad$ Multidisciplinary $\quad$ Journal, 6(1), 56-83. https://doi.org/10.1080/10705519909540119

[20] Fang, F., Schei, V., \& Selart, M. (2018). Hype or hope? A new look at the research on cultural intelligence. International Journal of Intercultural Relations. https://doi.org/10.1016/j.ijintrel.2018.04.002

[21] Racicot, B. M., \& Ferry, D. L. (2016). The Impact of Motivational and Metacognitive Cultural Intelligence on the Study Abroad Experience. Journal of Educational Issues, 2(1), 115-129.

[22] Fertonani, A., Brambilla, M., Cotelli, M., \& Miniussi, C. (2014). The timing of cognitive plasticity in physiological aging: a tDCS study of naming. Frontiers in aging neuroscience, $6,131$.

[23] Fischer, R. (2011). Cross-cultural training effects on cultural essentialism beliefs and cultural intelligence. International Journal of Intercultural Relations, 35(6), 767-775. https://doi.org/10.1016/j.ijintrel.2011.08.005

[24] Gudykunst, W. B., Ting-Toomey, S., \& Chua, E. (1988). Culture and interpersonal communication. Sage Publications, Inc. 
[25] Gumora, G., \& Arsenio, W. F. (2002). Emotionality, emotion regulation, and school performance in middle school children. Journal of School Psychology, 40(5), 395-413.

[26] Hauser, D. J., \& Schwarz, N. (2016). Attentive Turkers: MTurk participants perform better on online attention checks than do subject pool participants. Behavior Research Methods, 48(1), 400-407. https://doi.org/10.3758/s13428-015-0578-Z

[27] Hickman, G. P., Bartholomae, S., \& McKenry, P. C. (2000). Influence of parenting style on the adjustment and academic achievement of traditional college freshmen. Journal of College Student Development. 41(1), 41-54.

[28] Holtbrügge, D., \& Engelhard, F. (2016). Study abroad programs: Individual motivations, cultural intelligence, and the mediating role of cultural boundary spanning. Academy of Management Learning \& Education, 15(3), 435-455.

[29] Hu, L., \& Bentler, P. M. (1999). Cutoff criteria for fit indexes in covariance structure analysis: Conventional criteria versus new alternatives. Structural Equation Modeling: A Multidisciplinary Journal, 6(1), 1-55. https://doi.org/10.1080/10705519909540118

[30] Huff, K.C., Song, P., \& Gresch, E.B. (2014). Cultural intelligence, personality, and cross-cultural adjustment: a study of expatriates in Japan. International Journal of Intercultural Relations, 38, 151-157.

[31] Izard, C., Fine, S., Schultz, D., Mostow, A., Ackerman, B., \& Youngstrom, E. (2001). Emotion knowledge as a predictor of social behavior and academic competence in children at risk. Psychological Science, 12(1), 18-23.

[32] Jackson, D. N. (1976, September). The appraisal of personal reliability. Paper presented at the meetings of the Society of Multivariate Experimental Psychology, University Park, PA.

[33] Kuncel, N. R., Hezlett, S. A., \& Ones, D. S. (2004). Academic performance, career potential, creativity, and job performance: Can one construct predict them all. Journal of Personality and Social Psychology, 148-161.

[34] Lee, J. J., \& Rice, C. (2007). Welcome to America? International student perceptions of discrimination. Higher Education, 53(3), 381-409. https://doi.org/10.1007/s10734-005$4508-3$

[35] Lee, L. Y., Veasna, S., \& Wu, W. Y. (2013). The effects of social support and transformational leadership on expatriate adjustment and performance: The moderating roles of socialization experience and cultural intelligence. Career Development International, 18(4), 377-415. 
[36] Li, G., Chen, W., \& Duanmu, J. L. (2010). Determinants of international students' academic performance: A comparison between Chinese and other international students. Journal of Studies in International Education, 14(4), 389-405.

[37] Lin, J. C. G., \& Yi, J. K. (1997). Asian international students' adjustment: Issues and program suggestions. College Student Journal, 31(4), 473-479.

[38] Lin, Y., Chen, A. S., \& Song, Y. (2012). Does your intelligence help to survive in a foreign jungle? The effects of cultural intelligence and emotional intelligence on crosscultural adjustment. International Journal of Intercultural Relations, 36(4), 541-552. https://doi.org/10.1016/j.ijintrel.2012.03.001

[39] Lindenberger, U., \& Mayr, U. (2014). Cognitive aging: is there a dark side to environmental support?. Trends in cognitive sciences, 18(1), 7-15.

[40] MacNab, B. R. (2012). An experiential approach to cultural intelligence education. Journal of Management Education, 36(1), 66-94. https://doi.org/10.1177/1052562911412587

[41] Olson, L. G. (2008). An investigation of factors that influence academic achievement in Christian higher education: Emotional intelligence, self-esteem and spiritual wellbeing. Dissertation Abstracts International: Section B: The Sciences and Engineering, 69(5-B), 3254.

[42] Poropat, A. E. (2009). A meta-analysis of the five-factor model of personality and academic performance. Psychological Bulletin, 135(2), 322-338.

[43] Poyrazli, S., Arbona, C., Nora, A., McPherson, R., \& Pisecco, S. (2002). Relation between assertiveness, academic self-efficacy, and psychosocial adjustment among international graduate students. Journal of College Student Development, 43(5), 632-642.

[44] Presbitero, A. (2016). Culture shock and reverse culture shock: the moderating role of cultural intelligence in international students' adaptation. International Journal of Intercultural Relations, 53, 28-38.

[45] Project Atlas. (2019). A Quick Look at Global Mobility Trends [Infographic]. Project Atlas. https://www.iie.org/en/Research-and-Insights/Project-Atlas/ExploreData/Infographics/2019-Project-Atlas-Infographics

[46] Ramsey, J. R., Rutti, R. M., Lorenz, M. P., Barakat, L. L., \& Sant'anna, A. S. (2017). Developing global transformational leaders. Journal of World Business, 52(4), 461-473. 
[47] Raphael, K. (1987). Recall bias: a proposal for assessment and control. International Journal of Epidemiology, 16(2), 167-170.

[48] R Core Team. (2014). R: A language and environment for statistical computing. R Foundation for Statistical Computing. http://www.R-project.org/

[49] Rosseel, Y. (2012). Lavaan: An R package for structural equation modeling and more. Version 0.5-12 (BETA). Journal of Statistical Software, 48(2), 1-36.

[50] Rice, K. G., \& Slaney, R. B. (2002). Clusters of perfectionists: Two studies of emotional adjustment and academic achievement. Measurement and Evaluation in Counseling and Development, 35(1), 35-48.

[51] Roy, M., Lu, Z., Loo, B. (2016). Improving the international student experience: implications for recruitment and support. WES. http://knowledge.wes.org/WES-2016Research-Report-October.html

[52] Şahin, F., Gürbüz, S., Köksal, O., \& Ercan, Ü. (2013). Measuring cultural intelligence in the Turkish context. International Journal of Selection and Assessment, 21(2), 135-144.

[53] Schmidt, F. L., \& Hunter, J. (2000). Select on intelligence: In E. A. Locke (Ed.), Handbook of principles of organizational behavior (pp. 3-14). Oxford, England: Blackwell.

[54] Shu, F., McAbee, S. T., \& Ayman, R. (2017). The HEXACO personality traits, cultural intelligence, and international student adjustment. Personality and Individual Differences, $106,21-25$.

[55] Steffener, J., Brickman, A. M., Rakitin, B. C., Gazes, Y., \& Stern, Y. (2009). The impact of age-related changes on working memory functional activity. Brain imaging and behavior, 3(2), 142-153.

[56] Sternberg, R. J. (1986). A framework for understanding conceptions of intelligence. In R. J. Sternberg \& D. K. Detterman (Eds.), What is intelligence? Contemporary viewpoints on its nature and definition (pp. 3-15). Ablex.

[57] Sternberg, R. J., \& Detterman, D. K. (1986). What is intelligence?: Contemporary viewpoints on its nature and definition. Praeger Pub Text.

[58] Thomas, D., Stahl, G., Ravlin, E., Poelmans, S., Pekerti, A., Maznevski, M., Lazarova, M., Elron, E., Ekelund, B., Cerdin, J., Brislin, R., Aycan, Z. and Au, K. (2012). Development of the Cultural Intelligence Assessment. In Mobley, W., Wang, Y. and Li, 
M. (Eds.) Advances in Global Leadership (pp. 155-178). Emerald Group Publishing Limited.

[59] Thomas, D. C., Liao, Y., Aycan, Z., Cerdin, J. L., Pekerti, A. A., Ravlin, E. C., ... \& Moeller, M. (2015). Cultural intelligence: A theory-based, short form measure. Journal of International Business Studies, 46(9), 1099-1118.

[60] Thompson, R. (2018). A qualitative phenomenological study of emotional and cultural intelligence of international students in the United States of America. Journal of International Students, 8(2), 1220-1255. https://doi.org/10.32674/jis.v8i2.144

[61] Triandis, H. C. (2006). Cultural intelligence in organizations. Group \& Organization Management, 31(1), 20-26.

[62] UNESCO Glossary. (2020). International (or internationally mobile) students. UNESCO. http://uis.unesco.org/en/glossary-term/international-or-internationally-mobile-students

[63] University of Oxford. (2015). International trends in education 2015. University of Oxford. https://www.coursehero.com/file/16198048/International-Trends-in-HigherEducation-2015pdf/

[64] Wang, K. T., Heppner, P. P., Wang, L., \& Zhu, F. (2015). Cultural intelligence trajectories in new international students: Implications for the development of crosscultural competence. International Perspectives in Psychology: Research, Practice, Consultation, 4(1), 51-65.

[65] Ward, C., Fischer, R., Zaid Lam, F. S., \& Hall, L. (2009). The convergent, discriminant, and incremental validity of scores on a self-report measure of cultural intelligence. Educational and Psychological Measurement, 69(1), 85-105. https://doi.org/10.1177/0013164408322001

[66] Ward, A., Stoker, H. W., \& Murray-Ward, M. (1996). Educational measurement: Theories and applications. University Press of America.

[67] Ward, C., Fischer, R., Zaid Lam, F. S., \& Hall, L. (2009). The convergent, discriminant, and incremental validity of scores on a self-report measure of cultural intelligence. Educational and Psychological Measurement, 69(1), 85-105. https://doi.org/10.1177/0013164408322001

[68] Ward, C., Wilson, J., \& Fischer, R. (2011). Assessing the predictive validity of cultural intelligence over time. Personality and Individual Differences, 51(2), 138-142. https://doi.org/10.1016/j.paid.2011.03.032 
[69] Weiss, L. H., \& Schwarz, J. C. (1996). The relationship between parenting types and older adolescents' personality, academic achievement, adjustment, and substance use. Child Development, 67(5), 2101-2114.

[70] York, T. T., Gibson, C., \& Rankin, S. (2015). Defining and measuring academic success. Practical Assessment, Research \& Evaluation, 20(5), 2.

[71] Zhang, Y., \& Oczkowski, E. (2016). Exploring the potential effects of expatriate adjustment direction. Cross Cultural \& Strategic Management, 23(1), 158-183. 